Article

\title{
Thermal Degradation of Polystyrene (PS) Nanocomposites Loaded with Sol Gel-Synthesized ZnO Nanorods
}

\author{
Ashraf H. Farha ${ }^{1,2, *(\mathbb{D})}$, Abdullah F. Al Naim ${ }^{1}$ and Shehab A. Mansour ${ }^{3}$ (D) \\ 1 Department of Physics, College of Science, King Faisal University, P.O. Box 400, Al-Ahsa 31982, Saudi Arabia; \\ anaim2@kfu.edu.sa \\ 2 Semiconductors Technology Lab, Physics Department, Faculty of Science, Ain Shams University, \\ Cairo 11566, Egypt \\ 3 Advanced Materials/Solar Energy and Environmental Sustainability (AMSEES) Laboratory, \\ Faculty of Engineering, Menoufia University, Shebin El-Kom 32511, Egypt; shehab_mansour@yahoo.com \\ * Correspondence: afarha@kfu.edu.sa
}

Received: 13 August 2020; Accepted: 19 August 2020; Published: 27 August 2020

\begin{abstract}
Thermal degradation of polystyrene/ZnO (PS/ZnO) nanocomposites was investigated in this study. PS/ZnO polymer nanocomposites were prepared by using $\mathrm{ZnO}$ nanorods as nanofillers that were prepared via the sol-gel route. The as-prepared $\mathrm{ZnO}$ nanoparticles showed nanocrystallites in rod-like shapes with a non-uniform hexagonal cross-section and diameter varying from 40 to $75 \mathrm{~nm}$. $\mathrm{PS} / \mathrm{ZnO}$ nanocomposites with $\mathrm{ZnO}$ nanoparticles content ranging from $0-3 \mathrm{wt} \%$ are prepared via the common casting method. Even dispersion for $\mathrm{ZnO}$ nanoparticles within as-prepared PS/ZnO nanocomposites was verified through SEM/EDX measurements. Thermal degradation of the samples was checked by using the thermogravimetric (TG) analysis and differential scanning calorimetry (DSC) under non-isothermal conditions and a constant heating rate of $10^{\circ} \mathrm{C} \mathrm{min}$. The thermal stability of the nanocomposite is elevated compared to that of pristine PS due to the addition of the $\mathrm{ZnO}$ nanoparticles. The homogeneity of the PS/ZnO nanocomposites is verified by systematic increases in thermal degradation with increasing $\mathrm{ZnO}$ content. The characterization degradation temperatures at different weight loss percentages of $\mathrm{ZnO}$ nanoparticles increase at high $\mathrm{ZnO} w \mathrm{t} \%$. Static activation energy of decomposing is based on TGA data. Activation energies showed some enhancement after the addition of $\mathrm{ZnO}$ nanorods into the PS matrix. Enhancing the thermal stability of PS with $\mathrm{ZnO}$ addition within the investigated $\mathrm{ZnO}$ concentration range is verified by TG, DSC results.
\end{abstract}

Keywords: ZnO nanoparticles; polystyrene PS; chemical synthesis; polymer nanocomposite; sol-gel; DSC; thermal properties

\section{Introduction}

Functional materials with improved electrical, mechanical, and thermal properties have received a lot of attention recently [1,2]. Polymer nanocomposites, which result from combining both organic and inorganic materials, are one of the important groups of functional materials. The introduction of nanoparticles with specific amounts within the polymer matrix results in improvements in many of the conventional physical properties, as well as showing synergistic effects on the properties of host polymers [3-5]. Such types of organic and inorganic materials combinations are resulting in new material(s) with high potential usage in broad types of applications [1-7]. The resulting improvements in the properties of the polymers include excellent mechanical durability, thermal stability, ease of processing, molding, and chemical resistance to reagents [5,7]. 
The aims of improving the properties of both components of the new combinations are because of their demand in many technological applications. Several properties of the polymers have been tuned by proper type and/or amount of nanoparticles that were used as polymers fillers. The incorporation of the inorganic nanomaterials such as $\mathrm{ZnO}$ nanoparticles into the organic polymer matrix resulted in polymer/ZnO nanocomposites that had excellent magnetic, mechanical and high thermal stability properties [5,8-10]. Enhancing the thermal stability of the nanocomposites is a crucial aspect for many of their industrial applications [7,11-13].

In general, the great attention that has been paid to the polymers in recent years was because of their important applications in different fields. Polymers are used as sensors, light-emitting diodes, and various solar applications [14,15]. One of the interesting polymers that received a lot of this attention is polystyrene (PS). PS attracted attention due to its interesting optical and superior thermal and chemical stability features [15]. The good properties of PS included high optical transparency, very good electrical insulation, high thermal resistance, low density, excellent mechanical durability, and convenience of processing and molding $[5,10,14-16]$. All these advantages are making it an essential element in lots of market applications such as product packaging, extruded sheets and electronics [17,18]. Although it has all of these previous advantages, still there are some shortcomings, such as its high flammability and severe dripping during combustion $[9,19]$. Some means were proposed for overcoming such shortcomings. One way is blending PS with one or two or more polymers with different physical properties for enhancing the properties of resulting polymer materials $[6,20]$. Another way to overcome these shortcomings of PS is by attaining PS-new materials with enhanced properties through the nanocomposites approach. Most of the research studies that have been done to improve the thermal stability of PS polymer were done by adding different types of inorganic nanoparticles as fillers [21]. PS nanocomposites with carbon nanoparticles fillers were reported [5,10,15,22]. Among the inorganic fillers that have been added into the PS matrix are $\mathrm{ZnO}$ nanoparticles. Wacharawichanant et al. [6] reported no effect of the addition of $\mathrm{ZnO}$ of glass transition temperature $\mathrm{T}_{\mathrm{g}}$ of $\mathrm{PS} / \mathrm{ZnO}$ blends with other polymers and they also reported improvements in the thermal degradation of the blends as $\mathrm{ZnO}$ content increased. Other work on $\mathrm{Ps} / \mathrm{ZnO}$ nanocomposites, for only one composition at $\mathrm{ZnO}$ of $5 \mathrm{wt} \%$, reported an increase of $\mathrm{T}_{\mathrm{g}}$ as $\mathrm{ZnO}$ content increased in the sample [23]. Other work showed that the introduction of commercial $\mathrm{ZnO}$ nanoparticles into the PS matrix causes a very slightly increase in $\mathrm{T}_{\mathrm{g}}$ [10]. Most of these previous works were done at specific concentration of $\mathrm{ZnO}$ or in a smaller range. No such work was reported on $\mathrm{ZnO}$ nanoparticles with rod-like shapes as nanofillers. The aim of this study is to check the effect of the addition of $\mathrm{ZnO}$ nanoparticles with rod-like shapes of concentrations $(0,0.5,0.7,1.0$, and $3.0 \mathrm{ZnO} w \mathrm{w} \%)$ on the thermal stabilization of the PS matrix. The thermal properties and thermal stability of the under-investigation samples were checked and reported. Thermal degradation mechanisms of PS/ZnO nanocomposites were also studied here.

\section{Experimental}

\subsection{Materials}

Polystyrene (PS) pellets provided by (Sigma-Aldrich, St. Louis, MO, USA) were used. N,Ndimethylformamide (DMF, (Alfa Aesar, Haverhill, MA, USA)) was used for the preparation of $\mathrm{PS} / \mathrm{ZnO}$ nanocomposites. $\mathrm{ZnO}$ nanocrystals in rod-like shapes that were synthesized using sol-gel route as reported elsewhere $[24,25]$ were used as nanofillers. In such a typical route, zinc acetate dehydrate $\left(\mathrm{Zn}\left(\mathrm{CH}_{3} \mathrm{COO}\right)_{2} \cdot \mathrm{H} 2 \mathrm{O}\right)$, isopropanol and diethanolamine $\left(\mathrm{HN}\left(\mathrm{CH}_{2} \mathrm{CH}_{2} \mathrm{OH}\right)_{2}, \mathrm{DEA}\right)$ (Sigma-Aldrich, St. Louis, MO, USA) were used as salt precursor, solvent and chelating agent, respectively.

\subsection{Preparation of $P S / Z n O$ Nanocomposites}

$\mathrm{PS} / \mathrm{ZnO}$ nanocomposites were produced by a simple solution casting method. The desired amount of PS was added to $20 \mathrm{~mL}$ of DMF and stirring until completely dissolved. Then the proper amount of $\mathrm{ZnO}$ nanocrystals powder was added to the solution with stirring and kept for $2 \mathrm{~h}$ at room temperature 
(RT). The obtained mixture was of a total mass of PS and $\mathrm{ZnO} 1 \mathrm{~g}$ for each sample. To obtain the nanocomposite films, the mixture was dispensed onto a petri dish and kept under vacuum at RT for one week for drying and/or getting rid of excess amounts of the DMF solvents. Homogenous PS/ZnO nanocomposite films of $\approx 0.2 \mathrm{~mm}$ thickness were obtained. The $\mathrm{ZnO}$ nanocrystal concentrations were varied by $0,0.5,0.7,1.0$, and $3.0 \mathrm{wt} \%$ to obtain different nanocomposite films. The samples were labeled according to $0,0.5,0.7,1.0$, and $3.0 \mathrm{wt} \%$ percentages, as PS0, PS0.5, PS0.7, PS1.0 and PS3.0, respectively. ZnO nanocrystals were obtained after calcination that was done at $600{ }^{\circ} \mathrm{C}$ for $6 \mathrm{~h}$, The structure of the obtained final product of $\mathrm{ZnO}$ nanopowders was examined and confirmed by X-ray diffraction (XRD) using -ray diffractometer (PANalytical X'Pert PRO MRD X with Cu K $\alpha$ radiation source (PANalytical Inc., MA, USA), field emission scanning electron microscope and Fourier transform infrared (FTIR) according to a previous study [8]. The thermogravimetry (TG) analysis for pure PS and the PS/ZnO nanocomposite films were carried out using a Shimadzu TGA-50H instrument. A mass of about $2 \mathrm{mg}$ of the under-investigation sample was uploaded into the TG platinum pan. A TG heating rate of $10{ }^{\circ} \mathrm{C} \mathrm{min}-1$ under nitrogen $\left(\mathrm{N}_{2}\right)$ atmosphere and with a flow rate

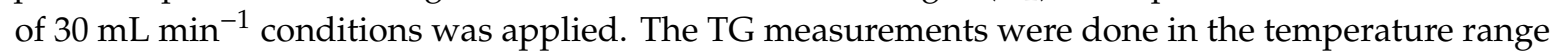
from RT to $600{ }^{\circ} \mathrm{C}$. The differential scanning calorimetric (DSC) measurements were done using DSC instrument (a SETARAM LabsysTM TG-DSC16 system, setaram instrumentation, France). For this cause, DSC alumina crucibles were charged with $20 \mathrm{mg}$ of the sample under examination. The DSC measurements were done under non-isothermal conditions through a constant heating rate of $10^{\circ} \mathrm{C}$ /min under an argon (Ar) gas atmosphere. The Ar gas dynamic flow of $25 \mathrm{~mL} \mathrm{~min}^{-1}$ in the temperature range from RT up to $600^{\circ} \mathrm{C}$ was used. Scanning electron microscopy (SEM) images were acquired using FE-SEM, (a Quanta FEJ2electron microscope, ThermoFisher Scientific Inc., Waltham, MA, USA). The morphology features and agglomeration rate of the $\mathrm{ZnO}$ nanoparticles were characterized by using a high-resolution transmission electron microscope (HR-TEM) (JEM-2100, JEOL Ltd., Tokyo, Japan). The elemental analysis of the prepared nanocomposite samples was examined by an energy dispersive X-ray spectroscopy (EDX) unit that attached to the Quanta FEJ2 electron microscope.

\section{Results and Discussion}

The morphologies of the PS/ZnO nanocomposite films were examined using the SEM tool. Figure 1 shows SEM images of the PS3.0 sample, as an example for the morphology of SEM images. Profound analysis of the morphology of the SEM image revealed a quite reasonable mixing between PS matrix and $\mathrm{ZnO}$ nanorods with some non-completely capped $\mathrm{ZnO}$ particles in rod-like shape on the surface of the film as shown in Figure 1a. The existence of the particles on the surface can be attributed to the high concentration of $\mathrm{ZnO}$ on this sample. Moreover, Figure $1 \mathrm{~b}$ reveals the formation of micron-sized agglomerations from $\mathrm{ZnO}$ nanorods. SEM confirms the existence of various dispersed $\mathrm{ZnO}$ nanorods that enabled a reasonable density of interfacial zones between the nanoparticles and polymer matrix. The elemental analysis in the specific regions of the rod-like shapes was examined using EDX as shown in Figure 2. The existence of $\mathrm{Zn}, \mathrm{O}$ and $\mathrm{C}$ elements in the investigated regions are clearly observed in this figure. This result is considered as evidence for the even dispersion of the $\mathrm{ZnO}$ nano-rods in the PS matrix. Such fine dispersion of the nanoparticles could be causing the enhancement of the thermal stability of the investigated PS/ZnO nanocomposite and it will be discussed afterwards. 


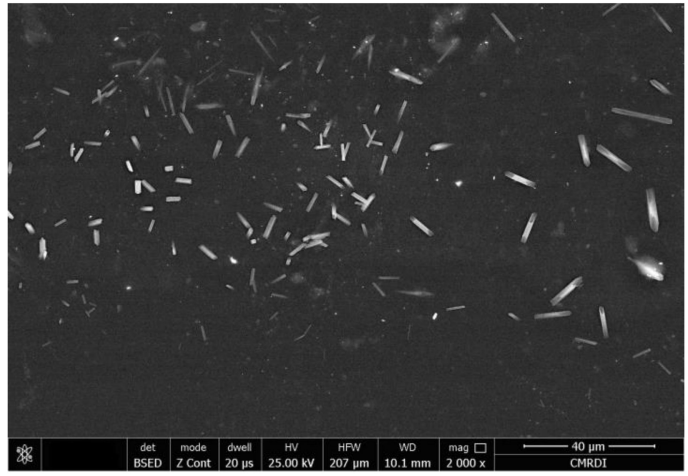

(a)

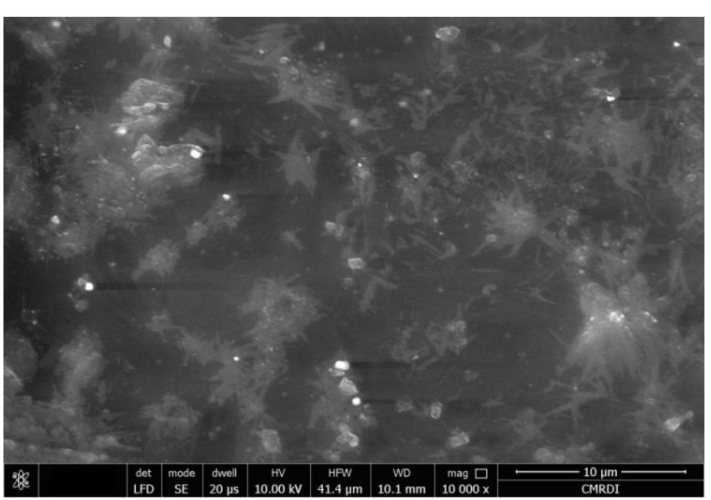

(b)

Figure 1. SEM images for PS3.0 sample at (a) $2000 \times$ (b) 100,000× magnifications.

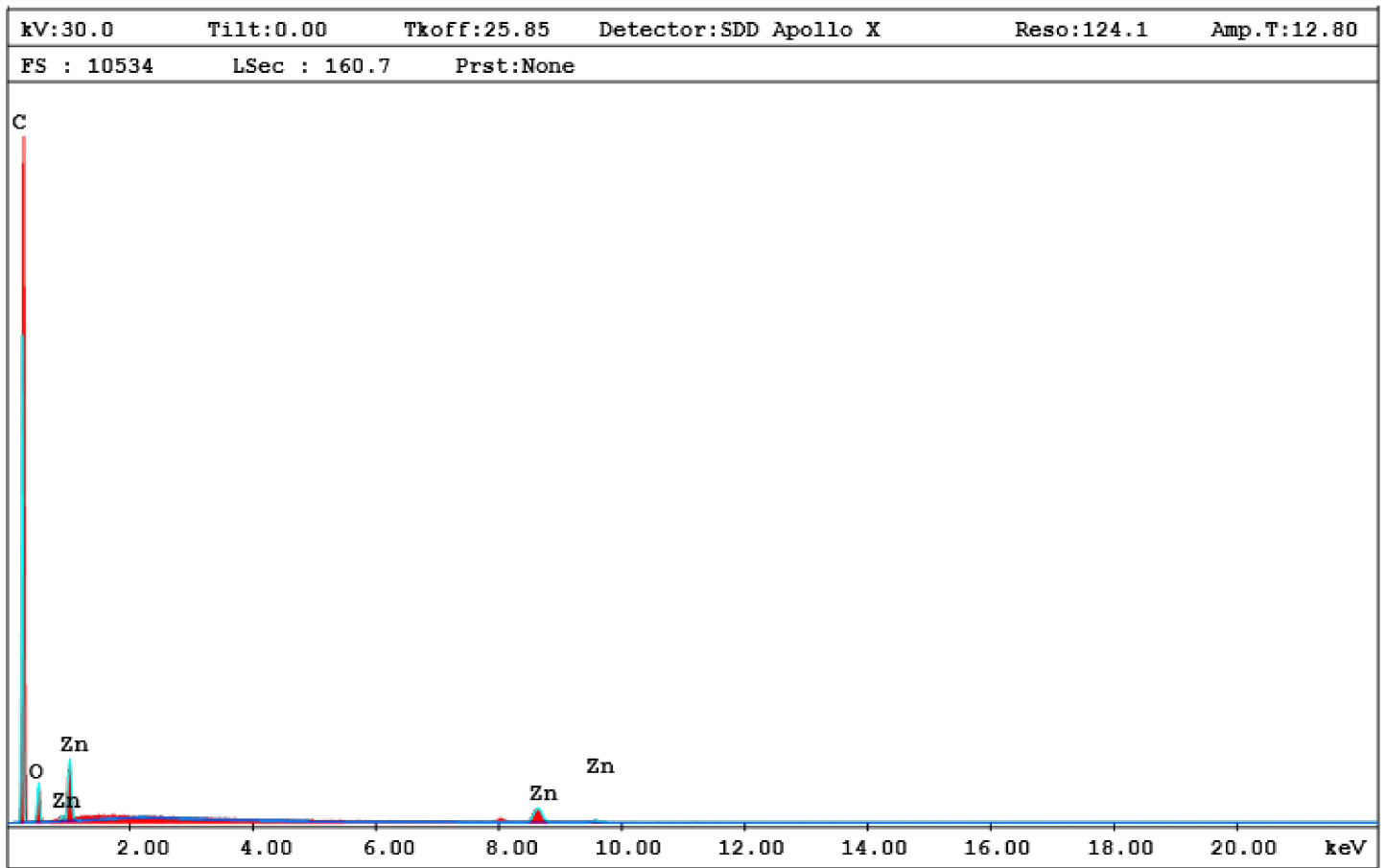

Figure 2. EDX analysis elemental analysis of the rod-like shape features PS3.0 of PS/ZnO nanocomposites.

Structural characterizations of $\mathrm{ZnO}$ nanorods were done using the XRD. Figure 3 shows the XRD pattern of the as-synthesized $\mathrm{ZnO}$ nanorods sample that was used as nanofiller in all PS samples with peaks identification on it. $\mathrm{ZnO}$ nanorods as seen from XRD patterns are crystallized in a typical wurtzite hexagonal structure for $\mathrm{ZnO}$ along (101) direction on the c-axis as a preferential growth direction. Hence all presented XRD peaks in the pattern are identical to that of the $\mathrm{ZnO}$ wurtzite structure. No other peaks were identified in the pattern for any other $\mathrm{ZnO}$ phase which confirms the single phase of as-synthesized $\mathrm{ZnO}$ sample. An average crystallite size (D) of about $39 \mathrm{~nm}$ using Scherer formula $D=\frac{0.94 \lambda}{W_{h k l} \cos \theta}$, where $\lambda=1.5406 \AA$ is the wavelength of used X-ray beam, $W_{h k l}$ is the full width at half maximum (FWHM) of the XRD peaks, and $\theta$ is the diffraction angle. The lattice constants of the wurtzite unit cell, $\mathrm{c}=5.2060 \AA$ and $\mathrm{a}=3.2462 \AA$ with $\mathrm{c} / \mathrm{a}=1.603$ and unit cell volume of $47.51 \AA^{3}$, were obtained which are matching that of the standard $\mathrm{ZnO}$ wurtzite unit cell [26]. 


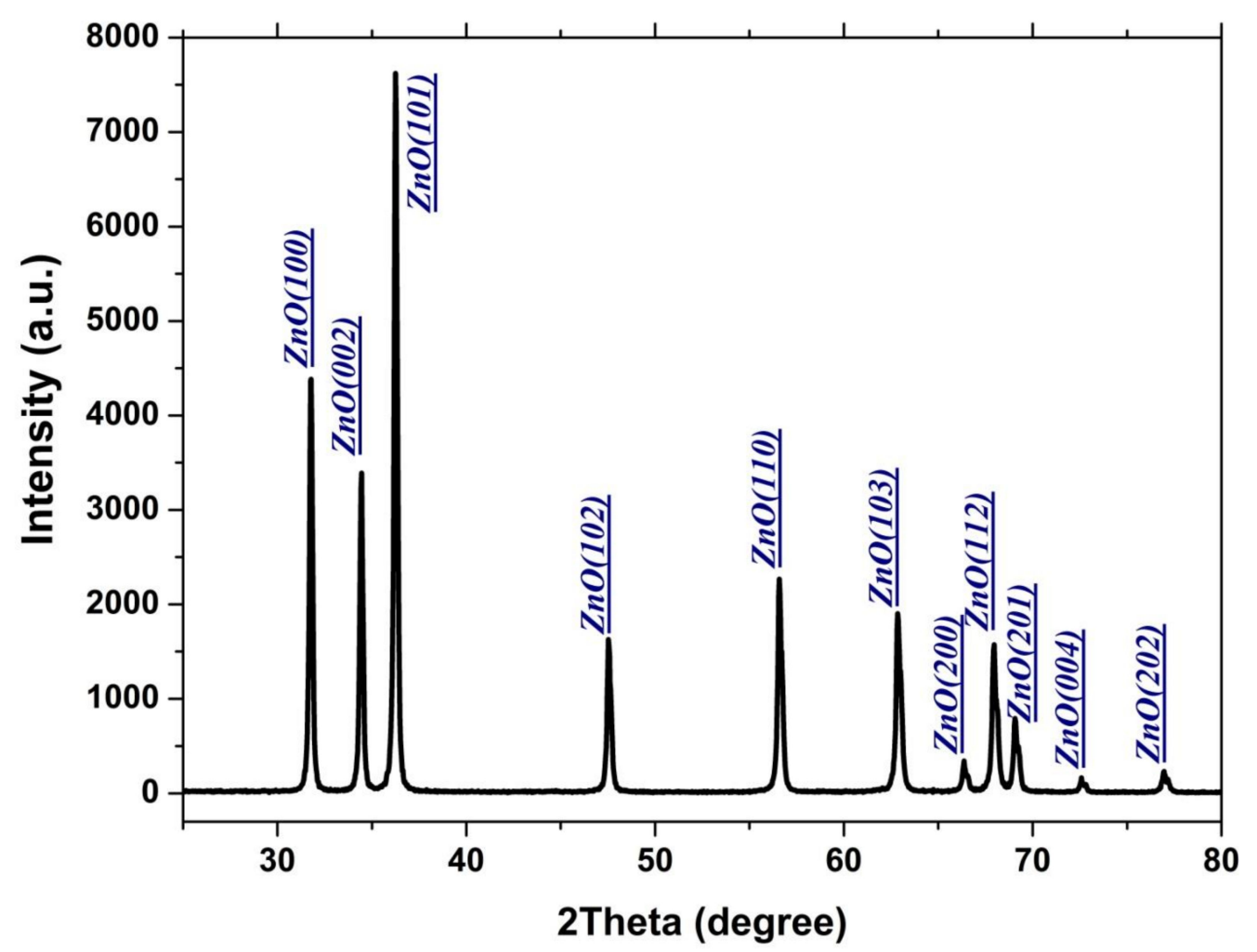

Figure 3. XRD diffrasction pattern of as-synthized $\mathrm{ZnO}$ nanoparticles used as PS nanofillers.

Figure 4 shows HR-TEM images for the as-synthesized $\mathrm{ZnO}$ nanorods. As can be seen from TEM the micrograph images reveal the formation of $\mathrm{ZnO}$ nanorods with some agglomeration as seen in the lower magnification TEM image of Figure 4a. Small nanosized rods are tending to agglomerate as a result of higher surface energy as well as their high surface to volume ratio.

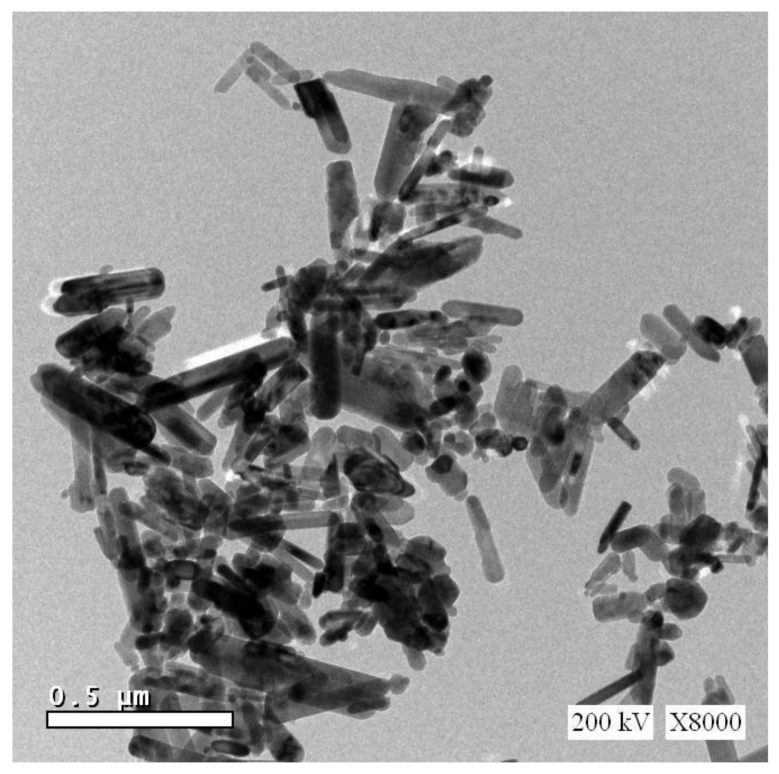

(a)

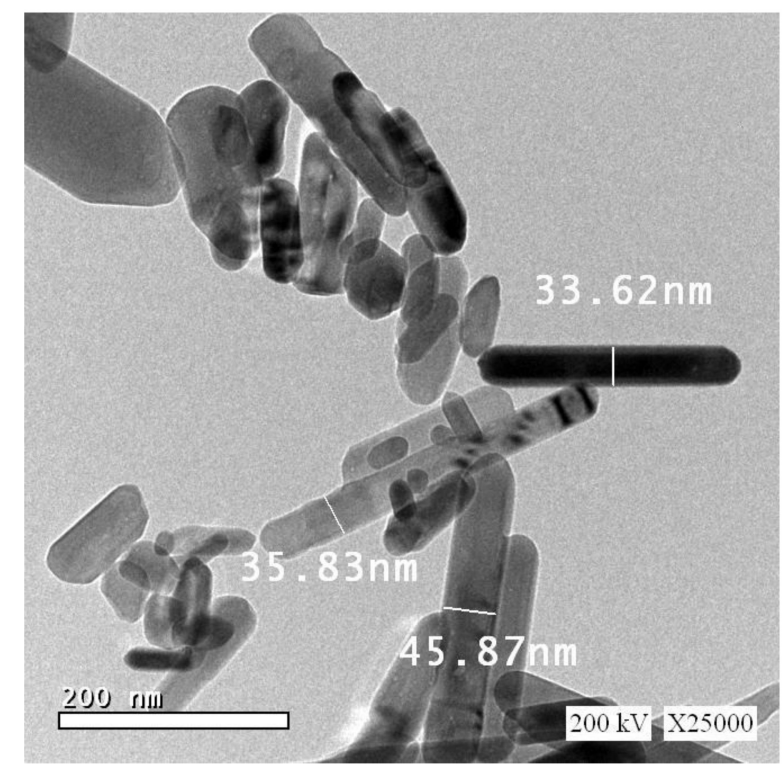

(b)

Figure 4. HR-TEM microgrph imges of as-synthized $\mathrm{ZnO}$ nanoparticles that used as PS nanofillers at two different mganfications, (a) $8000 \times$ and (b) 25,000×. 
The obtained $\mathrm{ZnO}$ nanorods showed good dispersion and distribution to be used as nanofillers in the PS polymer matrix. Figure $4 \mathrm{~b}$ depicts a higher magnification TEM image for as-synthesized $\mathrm{ZnO}$ nanrods. Figure $4 \mathrm{~b}$ reveals that the sample refers to well-defined rod structures with mixed characteristic sizes. The values that marked the average diameter for the obtained nanorods are also shown in Figure $4 b$.

The thermal stability of the Zn/PS samples was checked using the thermogravimetry (TG) technique and their Derivative thermogravimetric DTG analysis. Figure 5 shows the TG and obtained DTG curves for pure PS and PS/ZnO nanocomposites under investigation. The TG curves of all the investigated samples were showing a single degradation step, as seen in Figure 5a. The remaining weight after the degradation is systematically increased as the $\mathrm{ZnO}$ nanoparticles content in PS nanocomposites was increasing, as shown in the enlargement inset of Figure 5a. Such a result refers to the homogeneity of the obtained nanocomposites. The characterization temperatures at different weight loss percentages of $\mathrm{ZnO}$ nanoparticles at $\mathrm{T}_{50}$ and $\mathrm{T}_{100}$ are summarized in Table $1 . \mathrm{T}_{50}$ and $\mathrm{T}_{100}$ are temperatures at which 50 and $100 \%$ of weight losses occurred. The characteristic temperatures show that the thermal stability of all the $\mathrm{ZnO}$ nanocomposites is higher compared to that of the pure PS sample. The values of the degradation characterization temperatures that are listed in Table 1 are generally showing a trend of increasing as $\mathrm{ZnO}$ content increases in the samples. This is confirming that the $\mathrm{ZnO}$ addition is enhancing the thermal stability of PS within the investigated concentration $\mathrm{ZnO}$ nanoparticles range. The delay in the polymer degradation as the $\mathrm{ZnO}$ nanoparticle content increases in the samples can be explained in view of the decreasing in the chains' mobility with dispersion of nanoparticles into the polymer matrices [27], since inorganic nanoparticle fillers are non-degradable material with very high surface areas. The high dispersion of the nanoparticles into the polymer matrix is an obstacle for the diffusion of the free radical and as a result a retarding in degradation of the nanocomposites is obtained [10]. Similar results were obtained for PS-based nanocomposites with various nanofillers as nanosilica [28-30] and carbon nanoparticles [5] as well as $\mathrm{ZnO}[10,11]$. The delay in the thermal degradation of such investigated nanocomposites was attributed to fine dispersions of used nanofillers. In addition, the high heat capacity and good thermal conductivity of $\mathrm{ZnO}$ nanoparticles made them act as good heat sinkers that overcame the amount of heat that the PS polymer backbone could gain and hence enhancement in thermal stability of the composites is attained [25].

Table 1. Characteristic temperatures, $\mathrm{T}_{50 \%}$ and $\mathrm{T}_{100 \%} \mathrm{~T}_{\mathrm{m}}$ and $\mathrm{T}_{\mathrm{p}}$ are temperatures at which $50 \%$ and $100 \%$ weight loss of $\mathrm{ZnO}$ nanoparticles occurs, endothermic temperature peak and peak position, respectively.

\begin{tabular}{ccccc}
\hline Sample & $\mathbf{T}_{\mathbf{5 0}}{ }^{\circ} \mathbf{C}$ & $\mathbf{T}_{\mathbf{1 0 0}}{ }^{\circ} \mathbf{C}$ & $\mathbf{T}_{\mathbf{P}}{ }^{\circ} \mathbf{C}$ & $\mathbf{T}_{\mathbf{m}}{ }^{\circ} \mathbf{C}$ \\
\hline PS-0 & 401 & 440 & 403.3 & 412.3 \\
PS-0.5 & 409.3 & 441 & 410.8 & 413.5 \\
PS-0.7 & 409 & 445 & 410.7 & 413.5 \\
PS-1.0 & 412 & 451 & 413.2 & 414.4 \\
PS-3.0 & 405.5 & 445 & 408.3 & 412.8 \\
\hline
\end{tabular}

Figure $5 \mathrm{~b}$ shows the obtained DTG curves of all PS/ZnO nanocomposites. For clear observation of DTG peak positions and their shifts, the enlargement of the DTG spectra are depicted for PS and $\mathrm{PS} / \mathrm{ZnO}$ nanocomposites as an inset of Figure $5 \mathrm{~b}$. In addition, it can be seen from Figure 5 that the peak position $\left(T_{p}\right)$ as well as the characterization temperatures of decomposition $\left(T_{50}\right.$ and $\left.T_{100}\right)$ for all PS/ZnO nanocomposites showed shifts to higher temperatures as compared to that of pristine PS. Such shifts are clear indications of the enhancement in the thermal stability of the polymer nanocomposites per addition of the $\mathrm{ZnO}$ nanoparticles into the polymer matrix. Similar results were reported for $\mathrm{PS} / \mathrm{ZnO}$ nanocomposites [31]. The thermal stability behavior for these nanocomposites may be due to two overlapped stages of degradation, The $T_{p}$ values of the samples showed an increase from $403.3^{\circ} \mathrm{C}$ for PS sample to $413.2{ }^{\circ} \mathrm{C}$ for PS1.0 sample. Table 1 illustrates the obtained $\mathrm{T}_{\mathrm{p}}$ values for $\mathrm{PS} / \mathrm{ZnO}$ nanocomposites. 
(a)

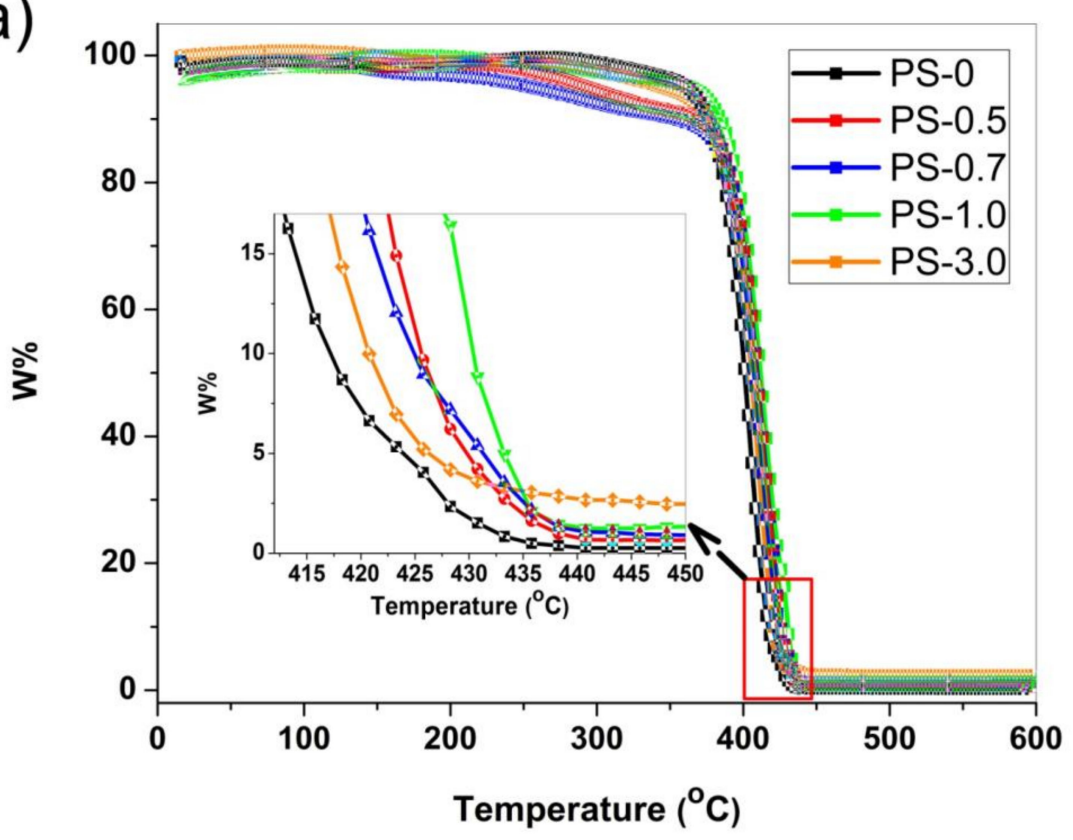

(b)

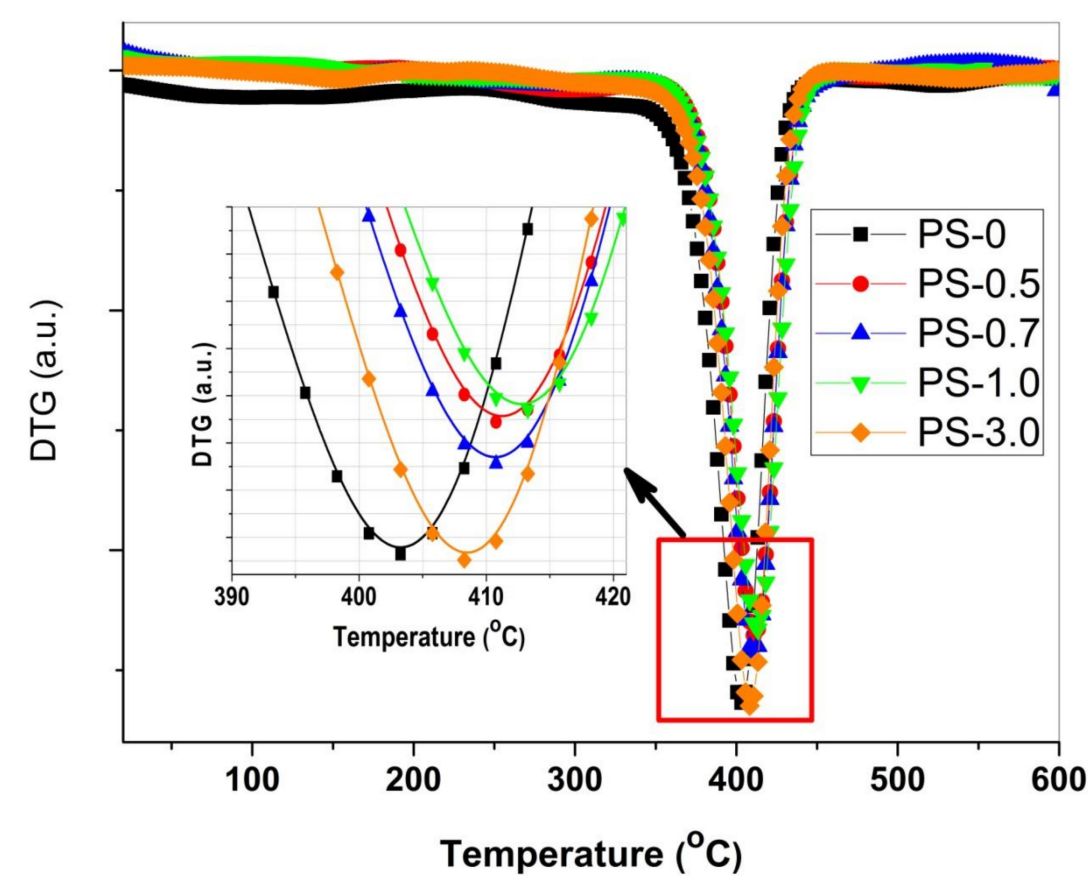

Figure 5. (a) TG curves for pure PS and PS/ZnO nanocomposites done at $10{ }^{\circ} \mathrm{C} \mathrm{min}^{-1}$ heating rate under $\mathrm{N}_{2}$ atmosphere and (b) DTG curves for pure PS and PS/ZnO nanocomposites.

For more investigation into the behavior of degradation for $\mathrm{Ps} / \mathrm{ZnO}$ nanocomposites in comparison with the pristine PS, the Coats-Redfern method was used for activation energy calculations [32,33]. In this method single heating rate data can be used for activation energy. TGA data of the under-investigation $\mathrm{PS} / \mathrm{ZnO}$ nanocomposites were used for this purpose. In this approach the constant TGA heating rate of weight loss was required [34]. In our calculations we used the Coats-Redfern method [33]:

$$
\ln \left(-\frac{\ln (1-\alpha)^{\mathrm{n}}}{\mathrm{T}^{2}}\right)=\ln \left[\frac{\mathrm{AR}}{\beta \mathrm{E}_{\mathrm{a}}}\left(1-\frac{2 \mathrm{RT}}{\mathrm{E}_{\mathrm{a}}}\right)\right]-\frac{\mathrm{E}_{\mathrm{a}}}{\mathrm{RT}}
$$


where $\alpha$ is the degradation fraction, $\mathrm{n}$ is the reaction order, $\mathrm{T}$ is absolute temperature, $\mathrm{A}$ is pre-exponential factor, $\beta$ is constant heating rate, $R$ is gas constant and $E_{a}$ is the activation energy of decomposing. The degradation fraction, $\alpha$, was obtained from $[5,35]$ :

$$
\alpha=\frac{\mathrm{W}_{\circ}-\mathrm{W}_{\mathrm{T}}}{\mathrm{W}_{\circ}-\mathrm{W}_{\infty}}
$$

where $\mathrm{W}_{\mathrm{o}}, \mathrm{W}_{\mathrm{T}}$ and $\mathrm{W}_{\infty}$ are remaining weights at the initial stage of the degradation process at temperature $\mathrm{T}$ and at the reaction end point, respectively.

Using the above equations for each TGA curve of PS/ZnO nanocomposites at heating rate, $\beta=10^{\circ} \mathrm{C} \mathrm{min}^{-1}$, and reaction order, $\mathrm{n}$ is assumed to be a reasonable assumption for many decomposing polymers [36]. The activation energies of decompositions can be obtained from a plot of the left side of equation (1) against $1 / \mathrm{T}$ and the slope of obtained straight lines for each sample is used to get activation Energy. Figure 6 shows the plot of plots of $\ln \left\{-\ln (1-\alpha) / T^{2}\right\}$ against $1000 / \mathrm{T}$ of the Coats-Redfern equation. The calculated activation energies of PS/ZnO nanocomposites are enlisted in Table 2 . The obtained value of the activation energy for pristine PS sample is $263.0 \mathrm{~kJ} / \mathrm{mole}$ and this is in good agreement with that reported before [35].

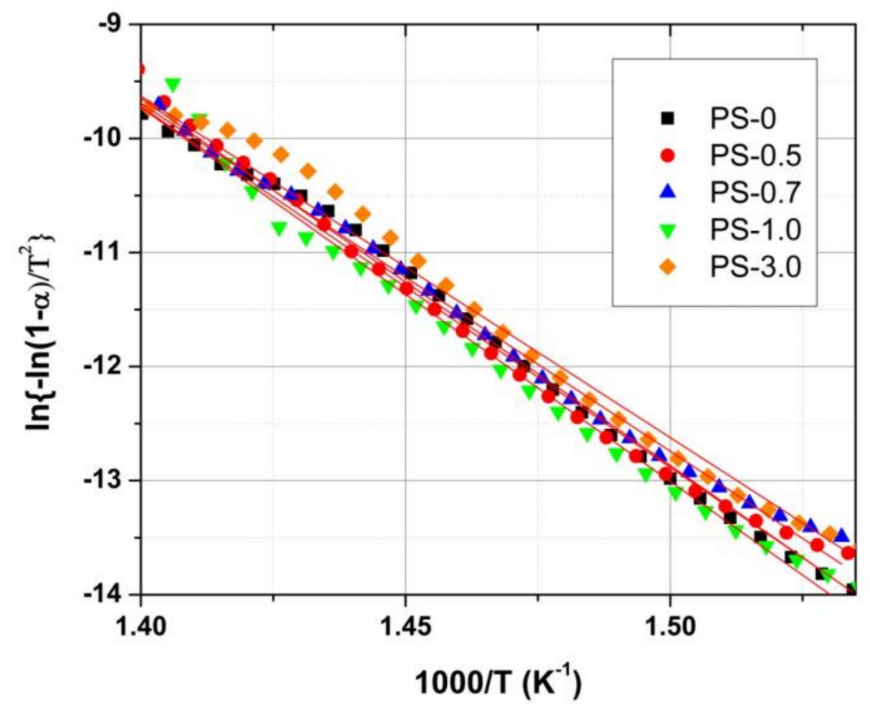

Figure 6. Plots of $\ln \left\{-\ln (1-\alpha) / \mathrm{T}^{2}\right\}$ against $1 / \mathrm{T}$ of Coats-Redfern equation from TGA data to obtain thermal degradation activation energies of PS/ZnO nanocomposites. Straight lines are fitting lines.

Table 2. Thermal degradation activation energies of pristine PS and PS ZnO nanocomposites obtained from Coats-Redfern method.

\begin{tabular}{ccc}
\hline Sample & Ea (kJ/mol) & $\mathbf{R}^{\mathbf{2}}$ \\
\hline PS-0 & 263.0 & 0.997 \\
PS-0.5 & 267.6 & 0.996 \\
PS-0.7 & 253.7 & 0.998 \\
PS-1.0 & 272.6 & 0.995 \\
PS-3.0 & 248.8 & 0.992 \\
\hline
\end{tabular}

The obtained Ea values are 263.0, 267.6, 253.7, 272.6 and $248.8 \mathrm{~kJ} / \mathrm{mol}$ for PS-0, PS-0.5, PS-0.7, PS-1.0 and PS-3.0 samples respectively. The activation energy of degradation for both PS- 0.5 and PS- 1.0 nanocomposites is enhanced by about $3-5 \mathrm{~kJ} / \mathrm{mol}$ in comparison with the pristine PS, due to more thermal stability of the nanocomposite samples.

The differential scanning calorimetry (DSC) curves for pure PS and PS/ZnO nanocomposites that are done at a heating rate of $10^{\circ} \mathrm{C} / \mathrm{min}$ are shown in Figure 7. Endothermic peaks which are 
related to the melting process of the samples are prominent in each curve for all the investigated samples. The obtained values of the melting endothermic temperature peak $\left(\mathrm{T}_{\mathrm{m}}\right)$ are also listed in Table 1. The highest value of $T_{m}$ was recorded for PS-1.0 sample. The values of $T_{p}$ are slightly varied with the variation of the $\mathrm{ZnO}$ content in the studied $\mathrm{PS} / \mathrm{ZnO}$ nanocomposites. Such results are in good agreement with that attained for other degradation characterization temperatures $\left(T_{50}\right.$ and $\mathrm{T}_{100}$ ). Therefore, PS-1.0 is considered the most stable sample of all studied nanocomposites. Here it is worth mentioning that the reduction in the values of all degradation characteristic temperatures for the highest $\mathrm{ZnO}$ wt $\%$ nanocomposite (PS-1.0) can be attributed to the increase of the probability of the agglomeration of nanoparticles. Such agglomeration has adverse effects on the thermal stability of the investigated nanocomposites due to the expected conversion from nanostructure to microstructure of the $\mathrm{ZnO}$ particles. So, the effect of the loaded nanoparticles $(1 \mathrm{wt} \%$ ) on protection of the macromolecular chains from thermal decomposition are reduced in comparison to other studied samples with lower concentrations.

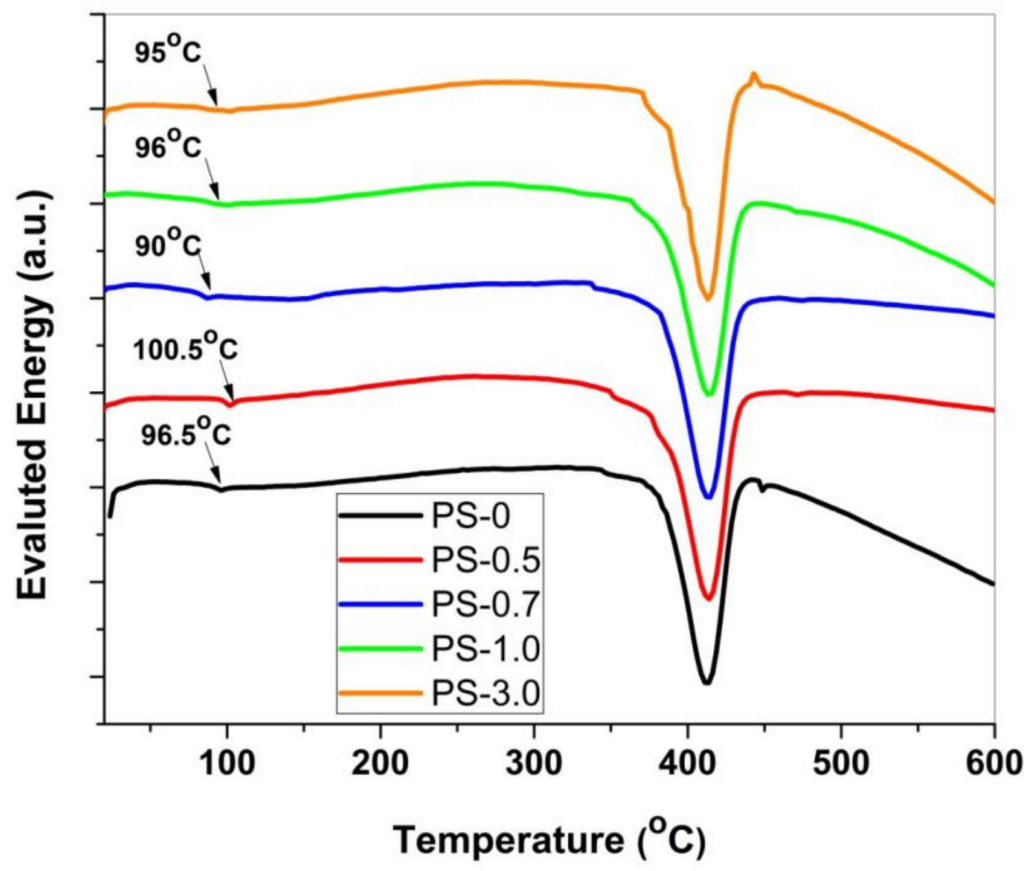

Figure 7. DSC curves were done at non-isothermal conditions of heating rate $10{ }^{\circ} \mathrm{C} / \mathrm{min}$ under a dynamic flow of Ar gas with a flow rate of $25 \mathrm{~mL} \mathrm{~min}^{-1}$.

Values of the glass transition temperature, $\mathrm{T}_{\mathrm{g}}$, of $\mathrm{PS} / \mathrm{ZnO}$ nanocomposites with change in the $\mathrm{wt} \%$ of $\mathrm{ZnO}$ rod-like nanoparticles, had a non-monotonic trend as shown in Figure 7. In fact, $\mathrm{T}_{\mathrm{g}}$ values did not show a unique trend with increasing of the $\mathrm{ZnO}$ nanofiller in the polymer nanocomposites. This is due to the competition of many factors which affects the degree of freedom of the polymer chains [37]. In most cases of nanocomposites, there are two main competitive factors. One of them is coating the existence organic layer, i.e., polymer, on the surface of nanoparticles which is leading to an increase in the degree of freedom and the entropy of the nanocomposite system and consequently the $\mathrm{T}_{\mathrm{g}}$ of nanocomposite decreased. The other factor, the presence of inorganic nanoparticles in the polymer matrix, is leading to a reduction in the density of configuration states of the macromolecules that enables the reduction of the disorientation entropy resulting in an increase in $T_{g}$ value. Here it is worth mentioning that the agglomeration of nanoparticles, the shape of the nanoparticles, and the degree of film homogeneity could be varied from one sample to another, especially when using the nanoparticles without any surface treatment or coupling agent. So, such variations in the investigated samples lead to a non-weighting factor which influenced in $\mathrm{T}^{\mathrm{g}}$ behavior. The increased value of $\mathrm{T}_{\mathrm{g}}$ in 
$0.5 \mathrm{wt} \%$ sample could be due to good confinement of the PS chains near the $\mathrm{ZnO}$ rather than affect by the interaction between PS and $\mathrm{ZnO}$ nanorods [10].

DSC results in Figure 7 also showed the presence of endothermic peaks in all samples around $440-450{ }^{\circ} \mathrm{C}$ which are obvious indications of the competence of the decomposition of PS/Zno nanocomposites. Also, very small endothermic peaks were obtained at a low temperature range close to $100^{\circ} \mathrm{C}$. The endothermic peak at this temperature value is for the water vapor. No other pronounced thermal peaks were observed besides the fundamental endothermic peaks. This result confirmed the formation of nanocomposites with high thermal stability as well as being in agreement with TG measurements that the degradation occurs via a single-step process.

\section{Conclusions}

$\mathrm{PS} / \mathrm{ZnO}$ nanocomposites loaded with $\mathrm{ZnO}$ nanorods in the range $0-3 \mathrm{wt} \%$ were obtained. $\mathrm{XRD}$ and TEM analyses affirmed the formation of $\mathrm{ZnO}$ nanorods with a good dispersion and matching the standard $\mathrm{ZnO}$ wurtzite structure. The thermal stability of the resulted PS/ZnO nanocomposites was very good because of the addition of $\mathrm{ZnO}$ nanorods in the investigation range. $\mathrm{Tg}$ increases on addition of $\mathrm{ZnO}$ by $0.5 \mathrm{wt} \%$ (PS-0.5) by $4{ }^{\circ} \mathrm{C}$ nanocomposites compared to pristine PS, then it remains nearly unchanged in the vicinity of $96^{\circ} \mathrm{C}$. The TG, DTG and DSC resulting data are referring to the most thermally stable nanocomposite obtained at $1 \mathrm{wt} \%$ of $\mathrm{ZnO}$ nanorods (PS-1). Moreover, all used concentration of $\mathrm{ZnO}$ nanorods have a positive effect on delaying the degradation process of the PS polymer chains as confirmed from the increasing in the $T_{50}$ and $T_{100}$ from TGA measurements for pristine PS and PS- 1 from 401 and $440{ }^{\circ} \mathrm{C}$ to 412 and $451{ }^{\circ} \mathrm{C}$, respectively. This is confirmed in the high dispersion of the $\mathrm{ZnO}$ nanorods in PS matrix. The degradation effect of $\mathrm{ZnO}$ nanorods was explained in view of the increase in the surface area of non-degradable material throughout the polymer matrix as $\mathrm{ZnO}$ content increases. In summary, the improvement of the thermal stability of $\mathrm{PS} / \mathrm{ZnO}$ nanocomposites is confirmed by activation energy calculations. Activation energies that were obtained from TGA data at constant heating rate are showing small enhancement by $3-9 \mathrm{~kJ} / \mathrm{mole}$ after the addition of $\mathrm{ZnO}$ nanorods. The role of used $\mathrm{ZnO}$ nanofillers is as an efficient heat sinker as well as a protective barrier for degradation process of polymer chains.

Author Contributions: Conceptualization, A.H.F., A.F.A.N. and S.A.M.; methodology, A.H.F. and S.A.M.; validation, A.H.F., A.F.A.N. and S.A.M.; formal analysis, A.H.F. and S.A.M.; investigation, A.H.F., A.F.A.N. and S.A.M.; resources, A.F.A.N. and S.A.M.; data curation, A.H.F., and S.A.M.; writing-original draft preparation, A.H.F.; writing-review and editing, A.H.F., A.F.A.N. and S.A.M.; supervision, A.F.A.N.; project administration, A.F.A.N.; funding acquisition, A.F.A.N. All authors have read and agreed to the published version of the manuscript.

Funding: The authors acknowledge Deanship of Scientific Research at King Faisal University, Al-Ahsa, Kingdom of Saudi Arabia, for providing support under grant number [17122004].

Conflicts of Interest: The authors declare no conflict of interest in this work.

\section{References}

1. Lan, T.; Kaviratna, P.D.; Pinnavaia, T.J. On the Nature of Polyimide-Clay Hybrid Composites. Chem. Mater. 1994, 6, 573-575. [CrossRef]

2. Yano, K.; Usuki, A.; Okada, A.; Kurauchi, T.; Kamigaito, O. Synthesis and properties of polyimide-clay hybrid. J. Polym. Sci. Part A Polym. Chem. 1993, 31, 2493-2498. [CrossRef]

3. Saujanya, C.; Radhakrishnan, S. Structure development and crystallization behaviour of PP/nanoparticulate composite. Polymer 2001, 42, 6723-6731. [CrossRef]

4. $\quad$ Rong, M.Z.; Zhang, M.Q.; Zheng, Y.X.; Zeng, H.M.; Walter, R.; Friedrich, K. Structure-property relationships of irradiation grafted nano-inorganic particle filled polypropylene composites. Polymer 2001, 42, 167-183. [CrossRef]

5. Mansour, S. Study of thermal stabilization for polystyrene/carbon nanocomposites via TG/DSC techniques. J. Therm. Anal. Calorim. 2013, 11, 579. [CrossRef] 
6. Wacharawichanant, S.; Thongbunyoung, N.; Churdchoo, P.; Sookjai, T.; Thongyai, S. Morphology and properties of poly(styrene-co-acrylonitrile)/poly(methyl methacrylate)/zinc oxide composites. J. Reinf. Plast. Compos. 2013, 32, 1112-1121. [CrossRef]

7. Zhang, Y.; Wan, Y.; Shi, Y.; Pan, G.; Yan, H.; Xu, J.; Guo, M.; Qin, L.; Liu, Y. Facile modification of thin-film composite nanofiltration membrane with silver nanoparticles for anti-biofouling. J. Polym. Res. 2016, $23,105$. [CrossRef]

8. Mansour, S.; Elsad, R.; Izzularab, M. Dielectric investigation of high density polyethylene loaded by ZnO nanoparticles synthesized by sol-gel route. J. Sol-Gel Sci. Technol. 2016, 80, 333-341. [CrossRef]

9. Chrissafis, K.; Bikiaris, D. Can nanoparticles really enhance thermal stability of polymers? Part I: An overview on thermal decomposition of addition polymers. Thermochim. Acta 2011, 523, 1-24. [CrossRef]

10. Chae, D.; Kim, B. Characterization on polystyrene/zinc oxide nanocomposites prepared from solution mixing. Polym. Adv. Technol. 2005, 16, 846-850. [CrossRef]

11. Ahmed, L.; Zhang, B.; Hawkins, S.; Mannan, M.S.; Cheng, Z. Study of thermal and mechanical behaviors of flame retardant polystyrene-based nanocomposites prepared via in-situ polymerization method. J. Loss Prev. Process Ind. 2017, 49, 228-239. [CrossRef]

12. Alaee, M.; Arias, P.; Sjödin, A.; Bergman, Å. An overview of commercially used brominated flame retardants, their applications, their use patterns in different countries/regions and possible modes of release. Environ. Int. 2003, 29, 683-689. [CrossRef]

13. Morgan, A.B.; Gilman, J.W. An overview of flame retardancy of polymeric materials: Application, technology, and future directions. Fire Mater. 2013, 37, 259-279. [CrossRef]

14. Althues, H.; Henle, J.; Kaskel, S. Functional inorganic nanofillers for transparent polymers. Chem. Soc. Rev. 2007, 36, 1454-1465. [CrossRef]

15. Barala, M.; Mohan, D.; Sanghi, S.; Siwach, B.; Kumari, S.; Yadav, S. Optical properties of PS/ZnO nanocomposites foils prepared by casting method. AIP Conf. Proc. 2019, 2142, 150009.

16. Mostafaei, A.; Zolriasatein, A. Synthesis and characterization of conducting polyaniline nanocomposites containing ZnO nanorods. Prog. Nat. Sci. Mater. Int. 2012, 22, 273-280. [CrossRef]

17. Bourbigot, J.S.; Gilman, W.; Wilkie, C.A. Kinetic analysis of the thermal degradation of polystyrene-montmorillonite nanocomposite. Polym. Degrad. Stab. 2004, 84, 483-492. [CrossRef]

18. Walker, J.P.; Asher, S.A. Acetylcholinesterase-Based Organophosphate Nerve Agent Sensing Photonic Crystal. Anal. Chem. 2005, 77, 1596-1600. [CrossRef]

19. Bikiaris, D. Can nanoparticles really enhance thermal stability of polymers? Part II: An overview on thermal decomposition of polycondensation polymers. Thermochim. Acta 2011, 523, 25-45. [CrossRef]

20. Asaletha, R.; Kumaran, M.G.; Thomas, S. Thermal behaviour of natural rubber/polystyrene blends: Thermogravimetric and differential scanning calorimetric analysis. Polym. Degrad. Stab. 1998, 61, 431-439. [CrossRef]

21. Hu, Y.-H.; Chen, C.-Y.; Wang, C.-C. Viscoelastic properties and thermal degradation kinetics of silica/PMMA nanocomposites. Polym. Degrad. Stab. 2004, 84, 545-553. [CrossRef]

22. Alam, M.; Arif, S.; Shariq, M. Enhancement in Mechanical Properties of Polystyrene-ZnO Nanocomposites. Int. J. Innov. Res. Adv. Eng. 2015, 2, 122-129.

23. Jassim, A.N.; Alwan, R.M.; Kadhim, Q.A.; Nsaif, A.A. Preparation and Characterization of ZnO/polystyrene Nanocomposite Films Using Ultrasound Irradiation. Nanosci. Nanotechnol. 2016, 6, 17-23.

24. Mansour, S.A.; Elsad, R.A.; Izzularab, M.A. Dielectric properties enhancement of PVC nanodielectrics based on synthesized ZnO nanoparticles. J. Polym. Res. 2016, 23, 85. [CrossRef]

25. Japić, D.; Marinšek, M.; Crnjak Orel, Z. Effect of ZnO on the thermal degradation behavior of poly(methyl methacrylate). Nanocomposites 2016, 63, 9. [CrossRef]

26. Farha, A.H.; Mansour, S.A.; Kotkata, M.F. Structural, optical, and magnetic study of dilute magnetic semiconducting Co-doped $\mathrm{ZnO}$ nanocrystals synthesized using polymer-pyrolysis route. J. Mater. Sci. 2016, 51, 9855-9864. [CrossRef]

27. Yang, F.; Nelson, G.L. PMMA/silica nanocomposite studies: Synthesis and properties. J. Appl. Polym. Sci. 2004, 91, 3844-3850. [CrossRef]

28. Vaziri, H.S.; Omaraei, I.A.; Abadyan, M.; Mortezaei, M.; Yousefi, N. Thermophysical and rheological behavior of polystyrene/silica nanocomposites: Investigation of nanoparticle content. Mater. Des. 2011, 32, 4537-4542. [CrossRef] 
29. Bera, O.; Pilić, B.; Pavličević, J.; Jovičić, M.; Holló, B.; Szécsényi, K.M.; Špirkova, M. Preparation and thermal properties of polystyrene/silica nanocomposites. Thermochim. Acta 2011, 515, 1-5. [CrossRef]

30. George, J.J.; Bhowmick, A.K. Ethylene vinyl acetate/expanded graphite nanocomposites by solution intercalation: Preparation, characterization and properties. J. Mater. Sci. 2008, 43, 702-708. [CrossRef]

31. Tang, E.; Liu, H.; Sun, L.; Zheng, E.; Cheng, G. Fabrication of zinc oxide/poly(styrene) grafted nanocomposite latex and its dispersion. Eur. Polym. J. 2007, 43, 4210-4218. [CrossRef]

32. Coats, A.W.; Redfern, J.P. Kinetic Parameters from Thermogravimetric Data. Nature 1964, 201, 68-69. [CrossRef]

33. Suresh, K.; Kumar, M.; Pugazhenthi, G.; Uppaluri, R. Enhanced mechanical and thermal properties of polystyrene nanocomposites prepared using organo-functionalized NiAl layered double hydroxide via melt intercalation technique. J. Sci. Mater. Devices 2017, 2, 245-254.

34. Paulik, F.; Paulik, J. Simultaneous thermogravimetric and thermo-gastitrimetric investigations under quasi-isothermal and quasi-isobaric conditions. Anal. Chim. Acta 1973, 67, 437-443. [CrossRef]

35. Kokta, B.V.; Valade, J.L.; Martin, W.N. Dynamic thermogravimetric analysis of polystyrene: Effect of molecular weight on thermal decomposition. J. Appl. Polym. Sci. 1973, 17, 1-19. [CrossRef]

36. Paulik, J.; Paulik, F. "Quasi-isothermal” thermogravimetry. Anal. Chim. Acta 1971, 56, 328-331. [CrossRef]

37. Serenko, O.A.; Roldughin, V.I.; Askadskii, A.A.; Serkova, E.S.; Strashnov, P.V.; Shifrina, Z.B. The effect of size and concentration of nanoparticles on the glass transition temperature of polymer nanocomposites. RSC Adv. 2017, 7, 50113-50120. [CrossRef]

(C) 2020 by the authors. Licensee MDPI, Basel, Switzerland. This article is an open access article distributed under the terms and conditions of the Creative Commons Attribution (CC BY) license (http://creativecommons.org/licenses/by/4.0/). 